goose-quill, of which I made a tube, one end which, guided by my finger, I passed into the larynx, dne inflating the lungs with my breath, and emptying by pressure on the chest, which process I continued for more than half an hour, when I perceived slight motion of the abdominal muscles, and, still persevering, my efforts were crowned with success, and I delivered the child to the nurse crying lustily, much to the joy of the parents, as well as my own satisfaction. The child has since done well.

This case, I think, fully proves that we ought always to make the attempt at resuscitation in still-born children, and it also proves by what simple means it may be brought about. Had I lost the child, I should have blamed myself for having neglected taking with me, which I invariably do, an elastic catheter.

July, 1855.

oN

\section{THE SALINE TREATMENT OF CHOLERA.}

\section{Br A. LECKIE, Esq., C.M., Glasgow.}

From certain reports lately published I observe a decided inclination to underrate the saline treatment of Asiatic cholera. It is true the writers, or the parties who get up these reports, speak of the great difficulty of finding reliable and satisfactory data on the comparative effects of the various modes of treat ment; but when this is the case I think it very improper that imperfect deductions should be made, and given forth to the community as the results of scientific investigation.

I have had a good deal of experience in cholera, especially during the last two visitations, and have given particular attention to the various modes of treatment which have at various times been adopted by medical practitioners. The more I see, either in my own practice or in the published experience of others, the more I am convinced that the saline treatment is immeasurably the best that has yet been adopted, and, if properly carried out, would bring the mortality as low as probably any method that may yet be discovered. During the last visitation I had twenty-one cases, the greater number of them being more or less collapsed, yet all of them recovered. I am anxious to impress the minds of practitioners with the fact that salines are efficacious, not only in cholera, but also in diarrhoea. As proof of this I have had within the last year above one hundred and twenty cases of diarrhoea, in not one of which was either opium or astringents given, but simply the salines with two or three grains of calomel, yet not one of them merged into cholera.

In regard to cholera, I have invariably found that if opium or stimulants had been given at any period of its progress, the disease was much more difficult to sulodue. When such medicines are given in conjunction with the salines, no favourable effect can be expected; yet this is frequently done, and when fatal results ensue, the salines are pronounced a failure. They must be given alone, or the saline method gets no trial at all. Two cases which had been thus drugged before I saw them were the only two that suffered from consecutive fever. There is still another point which must be particularly attended to, and that is, to have faithful and vigilant nursing. In aggravated cases, unless great attention is given, nccasionally varying the salines to suit the particular condition of the patient, and carrying on the external appliances with regularity and vigour, we cannot expect favourable results.

The medical practitioner must not rest contented with giving general instructions; he must make frequent visits, scrntinize with a jealous eye the conduct of the nurses, and occasionally set to work with his own hands. If these things be properly attended to, the happiest effects may be expected, even in what might appear to be hopeless cases.

In order to show this, and to give some idea of the attention that is necessary in cases of advanced collapse, I subjoin a few particulars in reference to one of my latest cases.

Mrs. L - Bonhill, aged twenty-three, was seized with diarrhoea about two o'clock A.M. on the 20th of September, and with vomiting and severe cramps about seven o'clock after which she rapidly sank, and became cold. Medical aid was sent for about eight o'clock, but could not be got till about one o'clock P.M., when I visited her. I found her vomiting a fluid resembling rice-water; passing stools involuntarily; skin cold; face of a leaden hue, covered with a cold sweat; tongue cold and pale; breath cold; eyes sunk in their sockets, and turned upwards, surrounded by a dark areola; whispering voice; respiration very slow; pulse not perceptible; hands blue; and urine suppressed. First passed urine about two o'clock P.M. on the 23rd; first bilious stool about four o'clock A. M.

Sept. 24th.-Recovered.

Treatment, salines. She took about six dozen of saline powders of different kinds. I visited her every two or three hours.

The following is the method I generally adopted:-

For Diarrheea. - One of the saline powders to be taken in three-quarters of a tumbler of water; another two hours afterwards. Two grains of calomel to be taken two hours after the second saline powder. At the expiry of other two hours, take another saline powder, which is to be repeated every two hours till the diarrhoea abates.

For Cholerc. One of the saline powders to be taken every half-hour, hour, or two hours, according to the severity of the case. If the vomiting continues after taking three or four saline powders, half a drachm of the carbonate of soda, or a common effervescing soda powder, sometimes also a small piece of ice, should be given every half-hour or hour till the vomiting cease. Then again commence the saline powders, omitting the muriate of soda. Afterwards give them with the muriate of soda, and without, alternately.

When the patient is far advanced in the collapse stage, a, tablespoonful of salt, in three gills of water, or beef-tea, should be thrown up the bowels every three hours.

Avoid, in all stages of the disease, the taking of brandy or stimulants of every kind, or opium in any form, as they are highly pernicious. In all cases, apply mustard poultices to the stomach and bowels.

If the extremities are cold, apply jars with hot water; and for cramps, friction.

Diet, arrowroot and beef-tea.

Drink, cold water, common effervescing soda powders, or ice. Bonhill, Dumbartonshire, 1855.

\section{STONE IN THE BLADDER, COMPLICATED WITH}

\section{STRICTURE OF THE URETHRA IN A PATIENT AGED EIGHTY-SIX.}

LITHOTRITY; RECOYERT.

\section{BY FREDERICK WILKINSON, Esq., M.R.C.S.}

THE following case is worthy of notice, not only from its complications, but from its having occurred in perhaps the oldest patient on record in this country, upon whom the operation of lithotrity has been successfully performed. Thus, in 512 cases of lithotrity recorded in Mr. Coulson's work on this subject, I find that (op. cit. pp. 878) from the age of

\begin{tabular}{|c|c|c|c|c|c|}
\hline 1 to 2 & there are & & & & cases. \\
\hline 21 to 40 & ," & $\ldots$ & $\ldots$ & 80 & , \\
\hline 41 to 50 & ," & $\ldots$ & $\ldots$ & 124 & , \\
\hline 51 to 60 & , & $\cdots$ & $\ldots$ & 44 & 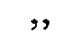 \\
\hline 61 to 80 & $"$, & $\cdots$ & $\cdots$ & 234 & " \\
\hline to 90 & ", & $\ldots$ & .. & 5 & , \\
\hline
\end{tabular}

W. G - has for the last fifty years been the subject of stricture of the urethra, which has necessitated the frequent use of the catheter, a No. 4 elastic being the largest which has been passed during that period. He has now been suffering for a long time with occasional diarrhcea, coupled with constant and urgent desire to pass urine, which is loaded with mucus and pus, alkaline, and very offensive, and he describes himself as being in a most wretched and miserable state.

The diarrhœe and general irritability being relieved by appropriate measures, a small sound was passed, and a calculus discovered high up in the right side of the bladder over its fundus.

Mr. Coulson, who had known the patient for many years, having been consulted, proposed an operation for the removal of the disease, intending to perform lithotomy or lithotrity as might be practicable, after attempting to dilate the urethra, the success or non-success of which I was to communicate to him.

On April 7th I passed a No. 5 elastic catheter, and found one stricture about three inches from the meatus, and another in front of the bulbous portion of the urethra. These instruments were gradually increased in size daily, retaining them in the bladder for twenty minutes, until the urethra was suffciently dilated to admit a No. 12 catheter. 